\title{
GERNOT MITTENDORFER: IF PEOPLE DO NOT HAVE THE RIGHT ATTITUDE, NOT EVEN THE BEST COACH CAN REPLACE IT
}

Gernot Mittendorfer is a member of the Management Board of Erste Group Bank AG responsible for Group Real Estate \& Leasing, Group Investment Banking, Group Large Corporates Banking, Local Corporate Banking, Corporate Support and Operations and GCIB Portfolio Management. The former CEO of Česká spořitelna talks, in his exclusive interview for CEBR, about the relationship between headquarters and subsidiaries, managers from CEE countries, gender equality in management, university relations and other interesting topics.

How do you feel about Czechs, Slovaks, and other former communist countries? Do you still see a major gap between them and western managers?

No, there is no gap anymore. I would say that you can still see that people here, even their chief men, are extremely hungry for developing themselves. And that is something that will have a very positive contribution to the development of these countries because you cannot find this in Western Europe anymore.

\section{Might this also help Central European managers to} be more successful in the international field?

For sure, today, you can see that there are many managers from this region who have reached international success. One big advantage of managers from this region is that they can handle German culture as well as Russian culture, for example. And that is difficult for us and we have to work hard in order to learn it. And knowledge of other language is an advantage, too.

What about the culture of the people? It has been twenty-three years since the fall of Communism. Are there still any cultural differences?

You don't feel the difference anymore. Managers who come from the countries with a communist history are much more capitalistically-oriented than people from countries which do not have this history. If you compare this country or Slovakia to Austria, in Austria people rely much more on the state, they think that they deserve everything and rely on their rights. That is not the case here and I am convinced it is right. People here are much more sceptical and, as a result, much more self-sufficient, which is good because that creates dynamism.

What do you think should be the goal for students and managers from this region in order to become more successful internationally? Does international experience help?

I think it is the quality of professors and teachers in general. The better access to experienced people you have, the better the chances of success are. It doesn't depend on whether you get international experience or whether it is skilled people who come here to do lectures or people who spend a semester or two in Prague as professors.

On the other hand, you need to have those managers and important personalities coming to provide education. How to bring them?

I think the university is doing a lot to bring them here and attract them and has a lot of contacts. I think that the key is to be the part of the network and then the whole thing develops automatically.

In the USA, a successful career in management depends on devoting a certain amount of time to provide your knowledge to the next generation, so lecturing etc. is a part of the definition of a successful manager. That's not the case here in Europe. This is something that could be the driving force on one hand, but on the other hand you need to give the universities financial means, so they can organize interesting events and attract interesting people because this is something that creates links between universities and business areas. 


\section{You often say the way out of the crisis might be connected with education; is this the reason why you are giving lectures at universities?}

For sure, there are a couple of things that need to be re-established and one of the keys is to re-establish growth to bring any kind of improvement because if we continue in the direction which we're heading right now, there's no change for the better. Another important element is education and investment in it because that means creating new opportunities. And I think that in Europe we have a tradition and history of bringing up highly skilled people and this is the strength that we've always had and it is something we have to focus on. We cannot just simply try to get the jobs that we've lost to some other regions back; I think that would be the wrong strategy.

\section{What do you personally get from giving lectures?}

I started it when I was a CEO at Česká Spořitelna and I was asked whether I could do a lecture for international students. For me, it was not a problem. Obviously, it requires some time and preparation because I take things seriously and when students see someone who is a CEO from the biggest bank in the country, they shouldn't get the impression that he is a complete idiot. So, I was investing some time in preparation and then I really enjoyed it. Since then, I've been collecting interesting charts and other material and adding them into my presentations. Last time I was counting the pages, I actually found out that there was too much information for the students, so I had to shorten it. I still keep my presentation updated with news about the latest development. Now, it costs a little bit more time because I am flying from Vienna but I have meetings here anyway, so when I agree to give a lecture, I just schedule my important meetings for the same day, it's not a big deal. Sometimes, you get a very interesting group of students and sometimes, they even give you a hard time but that's ok, that's why I enjoy it so much.

\section{Are students today different?}

I was studying in the eighties and knowledge of English was something that was not really necessary. At that time, the short-time prospects were good but you were stuck in your country whereas nowadays, in the time of internationalization, English is the key to success in the field of economics. Some of the students speak a couple of languages and already have very interesting CVs compared to the time when I was 25 or 27 years old. This is completely different from my time and I have a deep respect for them because I know how much effort they have to put into their studies.

\section{During your lecture you say that investors do not want excellent companies because they do not have such a big potential. Is it valid also for people?}

There is one thing that cannot be taught and that is attitude. If people do not have the right attitude, it cannot be replaced, not even by the best coaches or mentors. But skills can be learned and that is why we invest so much in our people, both in their personal and professional development. This is something that does not stop when you leave the university. Even I am taking courses sometimes, because development is so fast that if you stop learning, you will soon find yourself left behind.

\section{As a CEO of Česká Spořitelna, you were struggling with headquarters. Now you are on the opposite side and you are struggling with the subsidiaries. Has this somehow changed your perspective? And what is the situation between these two sides?}

First I'd like to say there was no struggling because the subsidiaries are not that small and they were always treated with deep respect. But it's true that sometimes you have to do certain things that you're not happy with. Now, from my position in Vienna, I have access to more information and I can understand and appraise both sides better than before. I support strong local management because I think it's more important to have excellent management teams in the individual countries than at the headquarters. Of course you should have excellent people on both sides but local management is extremely important and this is where I'm trying to promote. On the other hand, I'm trying to achieve more cooperation between these two sides because we have very creative and talented people but sometimes they tend to look just at their own kingdom and not at the whole empire. I still haven't found the best way to combine these two elements. So, this is something I'm still struggling with.

\section{Is there some advice that you would give to managers who are from small countries like the Czech Republic? Is there something they should do?}

The question is what kind of company you are working for. The Czech Republic is big enough for many companies and they really care about it. For career development, it's good to have experience working at headquarters for some time. When you are working on various projects you immediately recognize people with this kind of experience. They understand how it works at headquarters, who to talk to and they are much easier to deal with. Another important question is how to get attention from headquarters. Local management may have excellent ideas but they have to make managers at the headquarters aware of them. And as I said, the best way 


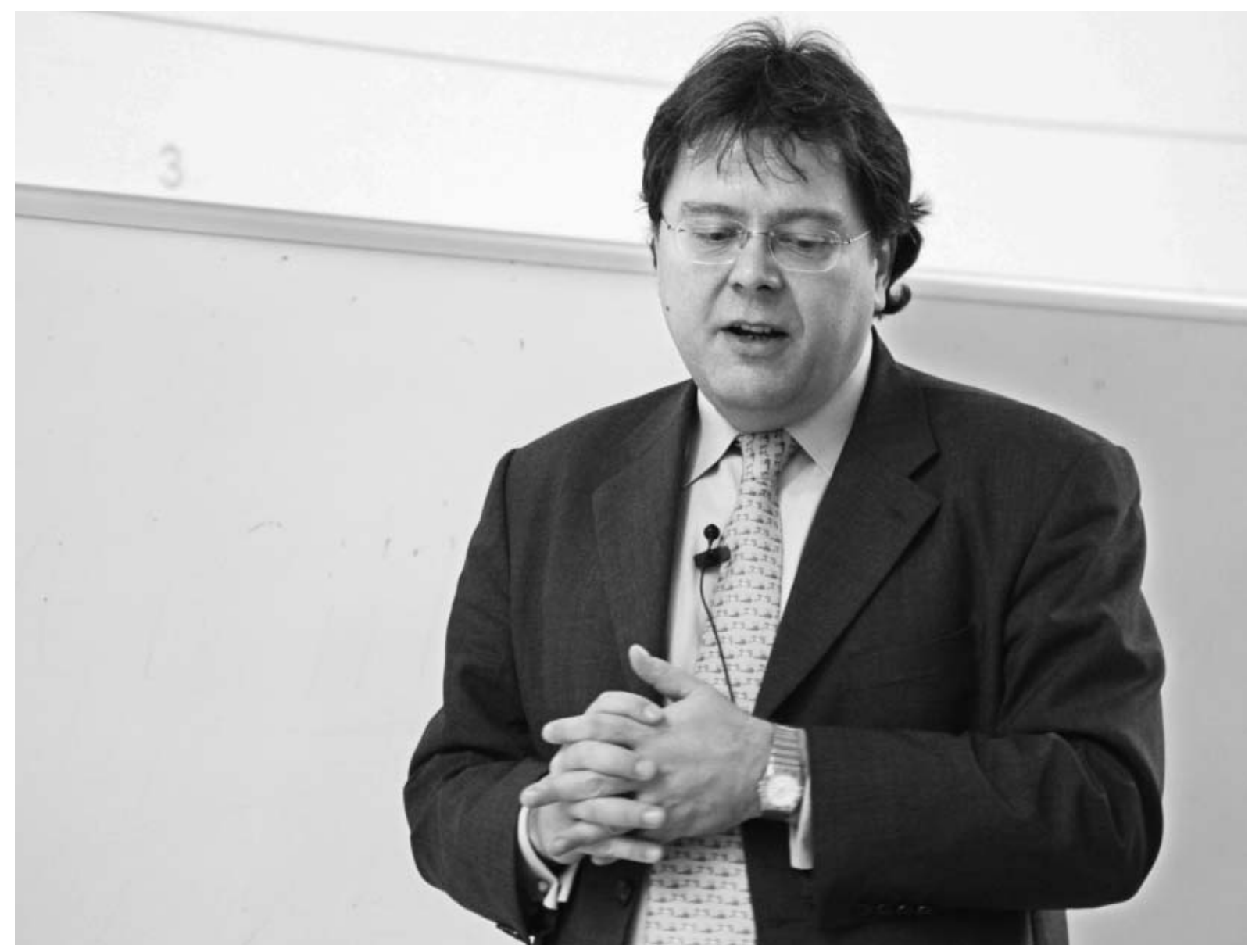

you can do it is to know somebody who has spent some time there or you have to spend some time there yourself.

\section{What personal abilities are important for this?}

I think you have to understand different cultures; you have to understand what motivates people to do certain things, so you should be good at psychology I guess. I'm not saying you have to study psychology but you should have a good understanding of culture and motivation and how they work together. Czech people are also very good at diplomacy and you should be able to find the right way to make the headquarters believe that your idea was actually their own idea. You shouldn't be too proud and you should care about success, not about being given the credit.

\section{What is your opinion on gender equality in management?}

Men took advantage of development in the earlier stages and there are still major differences between countries in that respect; some places it happened faster but for example in the Czech Republic, it took a while for women to become well-represented in this field.

\section{Can European law be helpful in this issue?}

I don't think so. Establishing quotas doesn't guarantee the right impact. Let me give you an example: When I worked at Česká Spořitelna, we had a couple of female managers who were taking care of the gender topic. And we had a discussion about whether it made sense to have quotas in certain areas. I thought that the only area where it made sense was in the development programs because that is where you bring up the generation of managers for the future. And then, you have a group of managers from which you select people for certain positions. And the bigger the share of women in that group is, the bigger the likeliness is of women getting promoted. So, you have to work on the group of available people and then the second step will happen automatically. At the end of the day, the best one, the most qualified person, should get the position and if you make this a fair, transparent process, then we will surely see women in the high positions. But you cannot enforce equality from the top because that will never lead to acceptance. The acceptance will come when you find women who are truly excellent at their jobs. 


\section{What should be the main field for companies} to concentrate on these days? How can they be successful when the crisis is still here?

I think companies have done very well so far and they prepared themselves well for this situation. They have been managing the working capital in the proper way and they have become more efficient. The crisis won't last forever but, as a company, you can't do much about it. Of course you can try to increase your market share in some areas but the companies are really careful about what they are doing and they are well-prepared for this situation.

\section{What should companies do about all the bad news regarding the crisis constantly coming from the media?}

We've been hearing bad news for years now and we are still around. In fact, some companies are doing quite well. It just seems we had a huge crisis that was basically caused by enormous debt accumulation and very relaxed monetary policy and now it's time to clean up the mess. Governments are having difficulties dealing with this, especially on the European level. This will take a while and then we'll go back to normal development. There will be a time when people won't be writing about the crisis anymore because they'll just get tired of it. The problem here is the economic model in which we were avoiding debt through inflation and now, when it stopped working, we don't know how to fix it. We have found ourselves in a low growth environment and we hope that we won't lose two decades like the Japanese. I think we can do much better. In my opinion, it's a bit of a mentality issue as well. We live in plenty but we are still complaining.

\section{What do you think we will say about our time in fifty} years, say in 2062?

I think it will be seen as a part of history when exaggeration caused a crisis and that leaders didn't know what to do. I think the assessment of this period will be about long and endless debates, strong opinions and complete wrong assessments of the situation.

\section{And what shall we say about, for example, 2017 at that time?}

I think we will be in a completely different situation in 2017. We've seen a combination of defaults, debt restructuring, tightening of spending, etc. So we'll be in a much better situation than we are right now and we will go back to normal growth again.

\section{What is the most interesting thing you like about your work?}

I like the fact that it's never boring. You always have new sets of challenges ahead of you and you work with different teams so everything's changing all the time and that never wears out.

And if you were not doing what are doing now, what would you love to be? Or what did you want to be when you were a child?

This is changing quite often but when I was young I wanted to be a guitar player in a rock band. I wasn't good enough to make it. I still think it would be fun, though. However, I don't have time for practicing.

\section{And what do you actually do in you spare time?}

That depends on where I am. I have an electric guitar and sometimes I play it. Now, when the winter is coming, I try to spend my weekends on the ski slopes.

\section{How would you characterise yourself?}

I would say I'm hard working and I always try to achieve the best results. I like to work with people and I think I have very good teams around me.

\section{How did you get such great teams around you?}

I've spent a lot of time choosing the team members. And being attached with universities is important as well because they have direct access to students and there might be some interesting people.

\section{What is your managerial motto or credo?}

I don't have a motto. I think that at the end of the day it's the customers who decide whether it was a successful day or not.

\section{What is the thing you are most proud of?}

I'm proud of bringing up my daughter. I think in kids you see whether you've made right decisions or not. For me, it's important that I'm satisfied with myself.

Authors

Tomáš Poucha and Zuzana Anna Palzer Marketing Institute

Faculty of Business Administration University of Economics, Prague Nám. W. Churchilla 4, 13067

Prague 3, Czech Republic tpoucha@mkti.cz 